\title{
Thymine and Guanine Base Specificity of Human Myeloma Proteins with Anti-DNA Activity
}

\author{
Moncef Zouali and B. David Stollar \\ Department of Biochemistry and Pharmacology, Tufts University Health Science Campus, Boston, Massachusetts 02111
}

\begin{abstract}
To further our understanding of the molecular basis of DNAautoantibody interactions, we have characterized the specificities of three IgG human myeloma proteins that bind DNA. We measured their binding to synthetic single- and double-stranded homopolynucleotides, random and alternating copolymers, oligonucleotides, and nucleotides or nucleosides conjugated to nonnucleic acid carriers. All three antibodies bound single-stranded nucleic acids, including both polyribonucleotides and polydeoxyribonucleotides. They varied in relative affinities for polynucleotides of varying base composition. Polymers containing the purines guanine or hypoxanthine and/or the pyrimidine thymine were most reactive with all three proteins. A myeloma protein that reacted with poly(G), poly(I), or poly(dT) also bound to the corresponding nucleosides or nucleotides conjugated to bovine serum albumin. None of the antibodies reacted with base-paired double-helical polynucleotides (double-stranded RNA, RNADNA hybrid or double-stranded DNA). The results indicate that base specificity is prominent in their reactions and that the accessible epitopes in single-stranded polynucleotides become masked upon base pairing in double-stranded helices. These findings suggest a model in which positions $\mathrm{N1}$ and $\mathrm{O6}$ of guanine and hypoxanthine and $\mathrm{N3}$ and $\mathrm{O} 4$ of thymine interact with amino acids of the antibody-combining site.
\end{abstract}

\section{Introduction}

Antibodies to DNA arise spontaneously in patients with systemic lupus erythematosus (SLE) ${ }^{1}$ and related diseases $(1,2)$. Many studies have been devoted to examination of their isotypic, idiotypic and paratopic expression (reviewed in reference 3 ) to determine whether certain subpopulations of anti-DNA antibodies are particularly pathogenic. In these studies, subpopulations with varying specificities have been identified. Some antiDNA antibodies appear to recognize in part the sugar-phosphate backbone of the DNA and cross react with phospholipids that lack purine and pyrimidine bases $(4,5)$. Many others, however, appear to be directed predominantly against other determinants that include the purine and pyrimidine bases (6).

Received for publication 24 April 1986.

1. Abbreviations used in this paper: dsDNA, double-stranded DNA; ELISA, enzyme-linked immunosorbent assay; HMP, human myeloma protein; SLE, systemic lupus erythematosus; ssDNA, single-stranded DNA.

J. Clin. Invest.

(c) The American Society for Clinical Investigation, Inc.

$0021-9738 / 86 / 11 / 1173 / 06 \quad \$ 1.00$

Volume 78, November 1986, 1173-1178
There are currently three sources of human anti-DNA antibodies available for study: $(a)$ polyclonal anti-DNA antibodies in lupus sera, which are heterogeneous with respect to isotype, affinity, and specificity (3), so that their detailed analysis is difficult; $(b)$ monoclonal antibodies produced by hybridomas or virus-transformed lymphocytes, derived from peripheral blood lymphocytes of lupus patients $(7,8)$, which have yielded much information on the degree of cross reactivity of individual immunoglobulins; and (c) human myeloma proteins (HMP) found in sera of patients with lymphoproliferative disorders such as multiple myeloma and Waldenström's macroglobulinemia. Several of the latter group have been found to exhibit autoantibody activity (reviewed in 9), including anti-DNA activity (1013). Myeloma proteins have also been found to share idiotypic determinants with human autoantibodies from lupus patients $(14,15)$. One example showed both antipolynucleotide reactivity and binding to a bacterial antigen (14).

To elucidate the molecular basis of DNA recognition by human autoantibodies, we studied three IgG human myeloma proteins with anti-DNA activity. We examined their reactivity with a number of synthetic single-stranded and double-stranded homo- and heteropolynucleotides. We also tested their binding to nucleosides and nucleotides attached to macromolecular carriers. This approach enabled us to delineate certain portions of the purine and pyrimidine bases of the nucleic acid molecule as prominent features of the epitopes for these immunoglobulins.

\section{Methods}

Human myeloma proteins. Three IgG myeloma proteins were isolated from the serum of three patients with multiple myeloma as described previously (11).

Nucleic acids and synthetic polynucleotides. Native calf thymus DNA, a double-stranded DNA (dsDNA), was purchased from Worthington Biochemical Corp. (Freehold, NJ) and purified further as described (16). The DNA was heated at $100^{\circ} \mathrm{C}$ for $10 \mathrm{~min}$ and quickly chilled for preparation of denatured single-stranded DNA (ssDNA). RNA was prepared from tissue culture cells (17). Poly(7-methylinosinate) was from Miles Laboratories, Inc., Elkhart, IN. All other synthetic polynucleotides were purchased from Pharmacia, Inc., Molecular Biology Division, Piscataway, NJ.

Oligonucleotides, nucleotides, nucleosides, bases, and conjugates. Guanosine and deoxyguanosine were from Calbiochem-Behring Corp., La Jolla, CA. 7-Methylguanosine, 8-bromoguanosine, 2'-deoxyguanosine, inosine, cytidine, and thymine riboside were from Sigma Chemical Co., St. Louis, MO. 7-Methylguanosine-5'-triphosphate and inosine-5'-phosphate were from Pharmacia, Inc.

Nucleosides and nucleotides were oxidized with sodium periodate and conjugated to amino groups of carrier molecules by the method of Erlanger and Beiser (18), modified as described previously (19).

Solid phase enzyme-linked immunosorbent assay (ELISA) for nucleic acid-binding antibodies. Polystyrene plates (Immunolon 1, Dynatech Laboratories, Alexandria, VA) were coated with poly(L-lysine) and nucleic acid and blocked with poly(L-glutamate) and $1 \%$ bovine serum albumin (BSA) as described (7). A sample of $150 \mu$ l of antibody diluted in phos- 
phate-buffered saline (PBS) with 1\% BSA was incubated in the wells for 60 min. Plates were washed with PBS containing 0.1\% Tween-20. Bound antibodies were detected with anti-human IgG (heavy chain-specific) conjugated to alkaline phosphatase (Sigma Chemical Co.). The substrate was p-nitrophenylphosphate $(1 \mathrm{mg} / \mathrm{ml}$ in $0.1 \mathrm{M}$ sodium carbonate, $\mathrm{pH}$ 9.5, $20 \mathrm{mM} \mathrm{MgCl}_{2}$ ). The absorbance at $405 \mathrm{~nm}$ was read with a microELISA reader (Dynatech Laboratories). To ensure the specificity of this ELISA antibody, samples were assayed simultaneously with wells treated in the same manner at all steps except that nucleic acid antigen was not added. All samples were tested in duplicate.

For competitive immunoassays, $100-\mu 1$ samples of varying concentrations of competitors in PBS- $0.1 \%$ BSA were incubated with equal volumes of anti-DNA antibody for $1 \mathrm{~h}$, and the mixtures were transferred to DNA-coated, BSA-saturated wells. The reaction was carried out as described above.

\section{Results}

DNA-binding myeloma proteins discriminate among polydeoxyribonucleotides of varying base composition. In a screening test of 105 human myeloma proteins for binding to denatured DNA, three (ROU, LAG, LAY) were found to have such activity (12). They are the subjects of this study. Their specificities were studied in finer detail by comparing DNA with many synthetic polynucleotides in competitive immunoassays. Poly(dT) effectively inhibited DNA binding by the three myeloma proteins at concentrations similar to those required for competition by soluble denatured DNA (Figs. 1 and 2). With antibody ROU, Poly(dC) competed at a 10-fold higher concentration and poly $(\mathrm{dG})$ at a still higher twofold concentration (Fig. 1). In contrast, poly(dA) did not compete for DNA binding by ROU (Fig. 1) or either of the other two proteins (not shown). The single-stranded random copolymer poly $(\mathrm{dC}, \mathrm{dA})$ was a slightly less effective competitor for ROU than the homopolymer poly( $\mathrm{dC})$. All three proteins showed the marked preference among the four homopolydeoxyribonucleotides for poly(dT) (Fig. 2), which competed even more effectively than ssDNA for proteins LAG and LAY (Fig. 2). The concentrations of ssDNA and poly(dT) required for binding were similar to those required for binding to hybridomaproduced anti-DNA antibodies or SLE serum antibodies (7, 16).

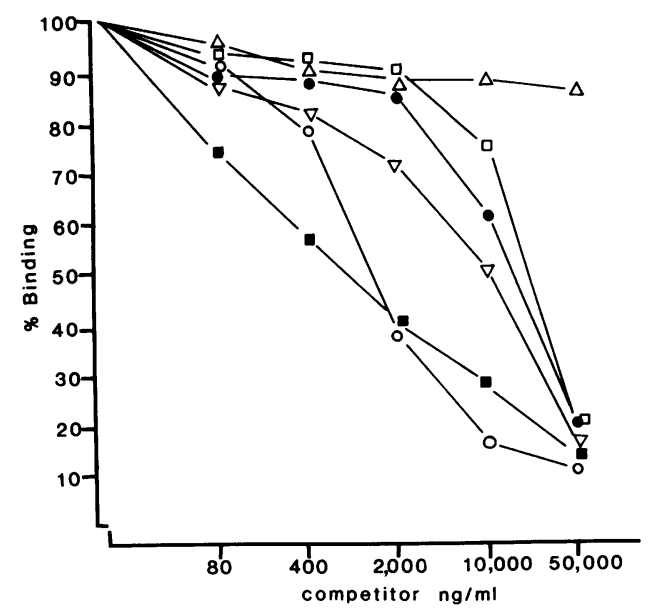

Figure 1. Inhibition of HMP ROU binding to ssDNA by polydeoxyribonucleotides. Varying amounts of competing polynucleotides were incubated with HMP ROU and added to ssDNA-coated polystyrene cells. The competitors were: poly(dT) (O); ssDNA (a); poly(dC) ( $\nabla)$; poly $(d A, d C)(\bullet) ; \operatorname{poly}(d G)(\square) ; \operatorname{poly}(d A)(\Delta)$.

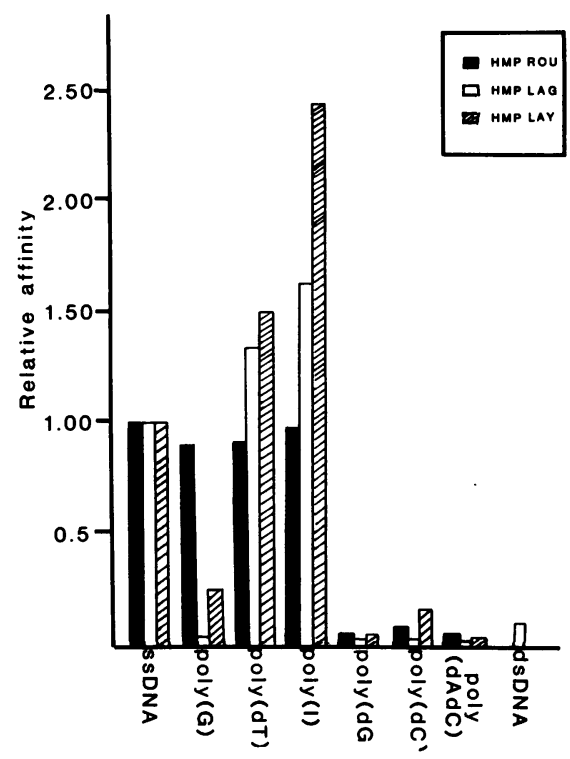

Figure 2. Comparison of the relative affinities of the three anti-DNA HMP for the positive polynucleotides. The relative affinity is calculated according to the formula: Relative affinity = amount of ssDNA required to achieve $50 \%$ inhibition of ssDNA binding/amount of competitor required to achieve $50 \%$ inhibition of ssDNA binding.

The myeloma proteins bind to polyribonucleotides. The three myeloma proteins bound to plates coated with poly(I) or poly $(G)$. These polyribonucleotides also competed effectively for binding of ROU to denatured DNA (Figs. 2 and 3). Poly(A) was a very weak competitor, poly(U) was still weaker, and poly(C) and total eukaryotic cellular RNA were not active even at very high concentrations (Fig. 3). Poly(I) was more reactive than poly(G) with proteins LAG and LAY (Fig. 2).

Double-stranded polynucleotides are not recognized by the anti-DNA myeloma proteins. Whereas poly(I) was very reactive with the three myeloma proteins, its incorporation into the double-helical poly $(\mathrm{I}) \cdot \operatorname{poly}(\mathrm{C})$ converted it into an inactive form for protein ROU (Fig. 3) or proteins LAG and LAY (not shown). Similarly, poly(dT) alone was very reactive (Fig. 1), but

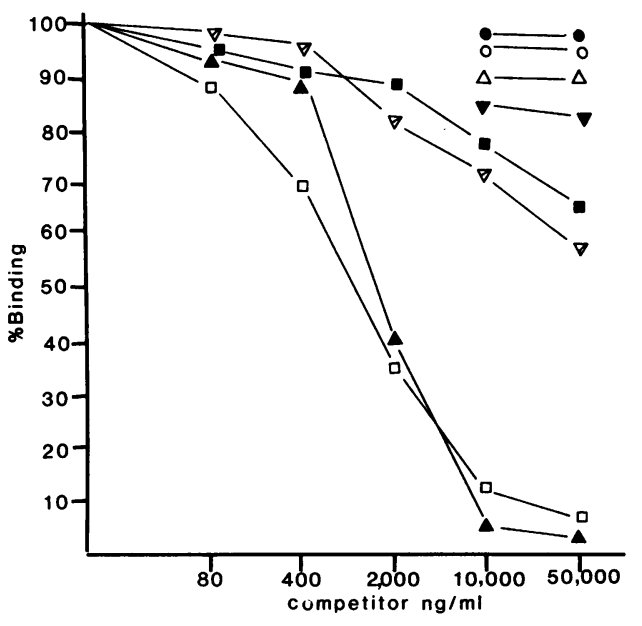

Figure 3. Inhibition of HMP ROU binding to ssDNA by polyribonu-

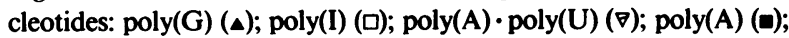

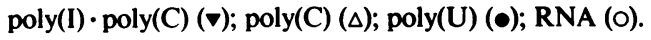


$\operatorname{poly}(d A) \cdot \operatorname{poly}(d T)$ was not reactive at all (data not shown). Neither was poly $(\mathrm{dG}) \cdot \operatorname{poly}(\mathrm{dC})$, though it was composed of two reactive homopolymers. The double-helical alternating copolymers poly(dA-dT), poly(dG-dC), and poly(dI-dC) were also unable to compete for binding to ssDNA by protein ROU, LAG, or LAY (data not shown). Native calf thymus DNA inhibited the binding of only one of the proteins, LAG, to ssDNA; $10 \mu \mathrm{g} /$ $\mathrm{ml}$ of native DNA caused inhibition similar to that caused by 1 $\mu \mathrm{g} / \mathrm{ml}$ of denatured DNA (Fig. 2).

The foregoing results are summarized in Table I, and a comparison of relative affinities of the positive polynucleotides is depicted in Fig. 2. The three antibodies exhibited individual patterns of relative affinity for the polynucleotide antigens, but all three distinguished among single-stranded polymers in a manner that suggested they may recognize the bases. This was substantiated by the loss of activity when the reactive homopolymers were incorporated into double-helical forms.

Anti-DNA antibodies interact with nucleosides and nucleotides presented on non-nucleic acid carriers. To define more precisely the epitopes recognized by the DNA-binding myeloma proteins and to examine the contribution of the individual bases and other nucleotide components in the absence of a continuous sugar-phosphate backbone, we tested the activity of nucleosides

Table I. Summary of the Competitive Assays of HMP Binding to ssDNA by Various Polynucleotides

\begin{tabular}{|c|c|}
\hline Polynucleotide & Inhibitory activity* \\
\hline \multicolumn{2}{|l|}{ RNA and analogues } \\
\hline RNA & - \\
\hline \multicolumn{2}{|l|}{ Polyribonucleotides } \\
\hline $\operatorname{poly}(G)$ & + \\
\hline $\operatorname{poly}(\mathrm{U})$ & - \\
\hline $\operatorname{poly}(\mathrm{C})$ & - \\
\hline $\operatorname{poly}(A)$ & - \\
\hline poly(I) & + \\
\hline \multicolumn{2}{|c|}{ Double-stranded polyribonucleotides } \\
\hline $\operatorname{poly}(A) \cdot \operatorname{poly}(U)$ & - \\
\hline $\operatorname{poly}(I) \cdot \operatorname{poly}(C)$ & - \\
\hline \multicolumn{2}{|l|}{ DNA and analogues } \\
\hline ssDNA & + \\
\hline dsDNA & $-\ddagger$ \\
\hline \multicolumn{2}{|l|}{ DNA homopolymers } \\
\hline $\operatorname{poly}(d T)$ & + \\
\hline poly(dG) & + \\
\hline poly(dA) & - \\
\hline poly $(\mathrm{dC})$ & + \\
\hline \multicolumn{2}{|l|}{ DNA random copolymer } \\
\hline poly $(d A, d C)$ & + \\
\hline \multicolumn{2}{|l|}{ DNA duplexes } \\
\hline $\operatorname{poly}(d A) \cdot \operatorname{poly}(d T)$ & - \\
\hline $\operatorname{poly}(d G) \cdot \operatorname{poly}(d C)$ & - \\
\hline \multicolumn{2}{|l|}{ DNA alternating copolymers } \\
\hline $\operatorname{poly}(d A-d T) \cdot \operatorname{poly}(d A-d T)$ & - \\
\hline poly $(d G-d C) \cdot \operatorname{poly}(d G-d C)$ & - \\
\hline poly $(\mathrm{dI}-\mathrm{dC}) \cdot \operatorname{poly}(\mathrm{dI}-\mathrm{dC})$ & - \\
\hline
\end{tabular}

* + represents an effective inhibition of binding of the HMP to ssDNA; - represents a lack of inhibition.

$\ddagger$ Only HMP LAG binding was slightly inhibited by dsDNA. and nucleotides, free or conjugated to a protein carrier. We found that the mononucleotides TMP, AMP, CMP, IMP, and GMP were unable to compete at concentrations up to $1 \mathrm{mM}$. Similarly, none of the nucleosides thymidine, inosine, cytidine, or 2'-deoxycytidine was able to compete for denatured DNA binding. Only guanosine caused a slight inhibition; deoxyguanosine was inactive. This latter result is consistent with the finding that poly(G) was a more effective inhibitor than poly(dG) (Fig. 2).

The inactivity of nucleotides and the weak inhibitory activity of guanosine compared with that of poly $(G)$ raised the possibility that multivalent interactions were required for measurable binding or that the binding sites encompassed more than one nucleotide. We therefore conjugated the mononucleotides GMP and IMP to a protein carrier. $\mathrm{GMP}_{20}$-BSA and $\mathrm{IMP}_{25}$-BSA effectively inhibited the binding of myeloma protein ROU to denatured DNA (Fig. 4). Similarly, we found that GMP $_{12}-\mathrm{KLH}$ could also compete for this binding (not shown).

To evaluate the importance of the phosphate groups in this activity, we examined the effect of a series of nucleoside-BSA conjugates on ssDNA binding. As can be seen in Fig. 5, guanosine $_{12}-\mathrm{BSA}$, inosine $\mathrm{e}_{11}-\mathrm{BSA}$, and thymidine ${ }_{15}-\mathrm{BSA}$ conjugates could inhibit the binding of protein ROU to ssDNA. The nucleoside concentrations required for competition were about 10 fold higher than those of nucleotide-BSA conjugates. Uridine ${ }_{11}$ BSA, cytidine ${ }_{13}-B S A$, and adenosine ${ }_{13}$-BSA were virtually inactive in this competitive assay. These findings indicate that the bases guanine, hypoxanthine, or thymine contribute substantially to the binding of the myeloma proteins, but the presence of the phosphate group in the nucleotide also contributes to it.

As shown in Figs. 1-3, the single-stranded homopolymers poly $(d T)$, poly $(d G)$, and poly(I) were recognized by these antiDNA antibodies whereas the double-stranded polynucleotides $\operatorname{poly}(d A) \cdot \operatorname{poly}(d T)$, poly $(d G) \cdot \operatorname{poly}(d C) ; \operatorname{poly}(I) \cdot \operatorname{poly}(C)$, poly $(\mathrm{dA}-\mathrm{dT}) \cdot \operatorname{poly}(\mathrm{dA}-\mathrm{dT})$, poly $(\mathrm{dG}-\mathrm{dC}) \cdot \operatorname{poly}(\mathrm{dG}-\mathrm{dC})$, and poly $(\mathrm{dI}-\mathrm{dC}) \cdot \operatorname{poly}(\mathrm{dI}-\mathrm{dC})$ were not. Thus, purine-pyrimidine pairing masks the target epitopes of these HMP. This phenomenon, together with the activity of thymidine-BSA, inosine-BSA, and guanosine-BSA and the lack of reactivity of cytidine-BSA or adenosine-BSA, suggests that these antibodies recognize determinants in the vicinity of $\mathrm{O} 6$ of purine bases and $\mathrm{O} 4$ of pyrimidine bases. This conclusion was examined further by testing

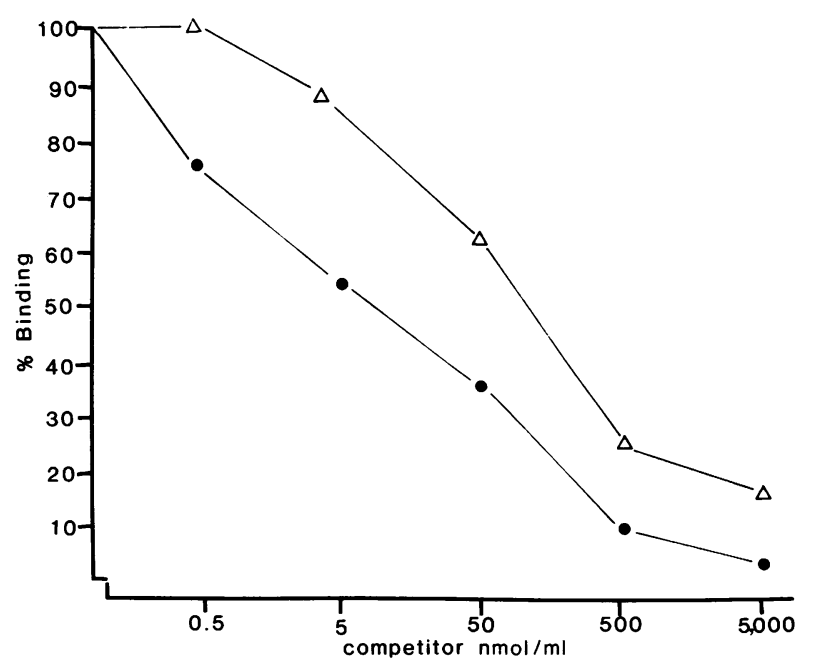

Figure 4. Effect of $\mathrm{IMP}_{25}$-BSA $(\Delta)$ and $\mathrm{GMP}_{20}-\mathrm{BSA}(\bullet)$ on binding of HMP ROU to ssDNA. 


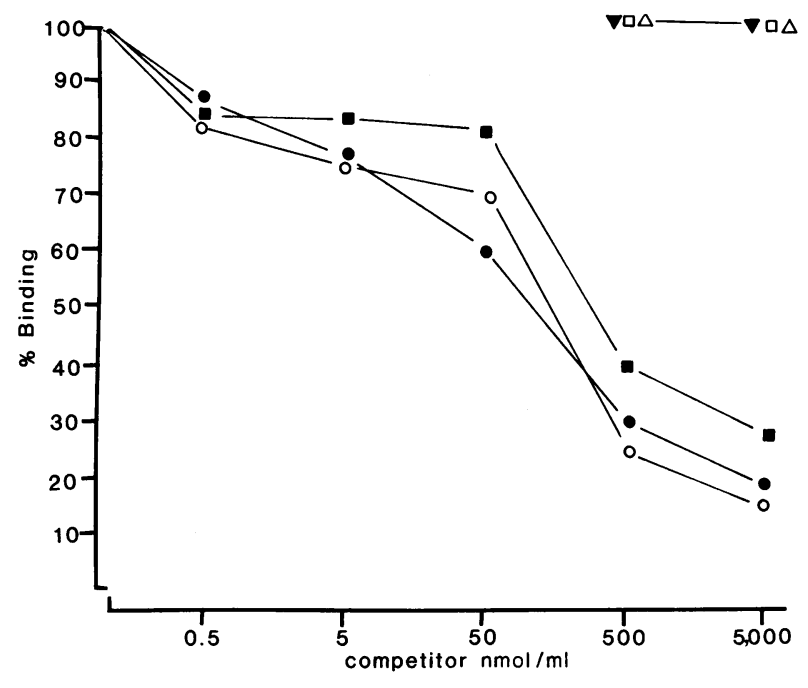

Figure 5. Effect of various nucleoside-BSA conjugates on binding of HMP ROU to ssDNA: Thymidine ${ }_{15}-$ BSA (๑); Guanosine ${ }_{12}-$ BSA (o);

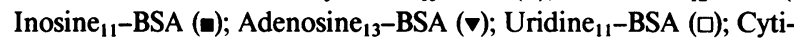
dine $_{13}-$ BSA $(\Delta)$.

the effect of substitutions at positions in the proximity of the putative epitopes of the active purine bases. Substitution at the C8 of guanosine, as in 8-bromoguanosine ${ }_{8}$-BSA, did not alter the activity of this nucleoside (not shown). Substitution at the N7 of hypoxanthine caused a dramatic reduction of activity, as seen in comparison with poly(I) and poly(7-methyl I) (Fig. 6).

\section{Discussion}

Shortly after anti-DNA antibodies in SLE sera were first identified (20-23), native and denatured DNA were found to react to different extents with different patients' sera $(24,25)$. Therefore, these autoantibodies may be directed against a variety of determinants in the bases or backbone of the nucleic acid. Some of the SLE antibodies react selectively with the denatured form. Among the first identified determinants of this type for SLE sera

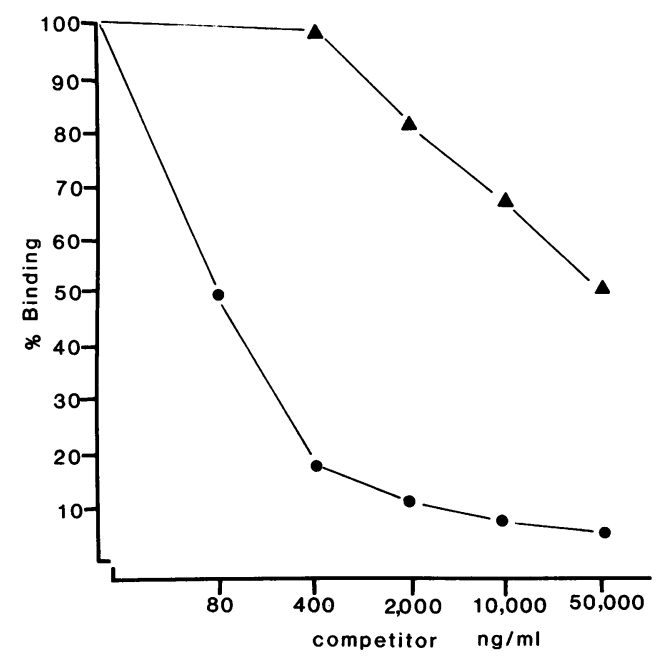

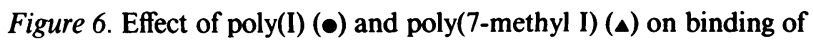
HMP LAG to ssDNA.

were a $(d T)_{5}$ sequence (26) and a single purine base (27). Other SLE antibodies bind both native and denatured DNA. Either double-stranded polynucleotides or denatured DNA effectively compete with these antibodies for native DNA binding $(24,25$, 28-30). These immunoglobulins may interact with portions of bases and/or polynucleotide backbone structures accessible in both forms of DNA $(29,30)$. Some also react with phospholipids, which have no purine or pyrimidine base $(4,5)$.

Because the precise positions of the bases involved in DNA binding of human antibodies are not known, we undertook a systematic study of the binding affinities of three HMP. Their reactions were tested with single- and double-stranded homoand copolymers of ribonucleotides and deoxyribonucleotides and with nucleoside-protein conjugates. Poly(dT), poly(I), and poly $(G)$ were the most reactive polynucleotides, and corresponding nucleosides conjugated to BSA were also able to compete for binding of the proteins to ssDNA. The primary nucleoside interactions were clearly with the bases rather than with modified ribose, through which the nucleosides were conjugated and which was identical in both active and inactive nucleosideprotein preparations. Comparison of reactive and unreactive nucleosides and polymers showed that the common features of the most reactive bases center around the 1-N and 6-carbonyl of hypoxanthine and guanine and the 3-N and 4-carbonyl of thymine (Fig. 7). Assignment of interaction to these sites is consistent with the nonreactivity of double-stranded polynucleotides, in which the same portions of the bases are involved in hydrogen bonding. It is also consistent with the strong binding of 8-Brguanosine, in which the bulky substituent on the 8-C does not interfere. It does not, however, explain the lack of binding to poly $(\mathrm{U})$ or uridine-BSA, both of which present a similar structure in this region of the base uracil. This lack of binding by uracil may indicate that the $5^{\prime}-\mathrm{CH}_{3}$ of thymine contributes to binding.

As these myeloma proteins are spontaneously arising human monoclonal antibodies, it is of interest to compare their antigenbinding properties with those of anti-DNA antibodies of autoimmune sera. In antigen-binding properties, the three HMP examined in this study are similar to SLE antibodies that react at least in part with determinants of the bases and are specific for denatured DNA. SLE antibodies that interact with the bases can also bind to nucleoside-protein conjugates $(6,31,32)$. Such conjugates can absorb nearly all of the anti-denatured DNA activity of certain murine lupus sera (6). Both murine and human lupus sera with anti-denatured DNA antibodies reacted predominantly with guanosine-protein conjugates in ELISA $(6,32)$,

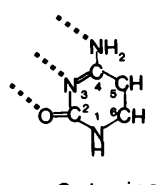

Cytosine

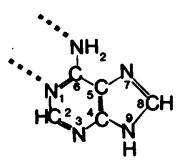

Adenine

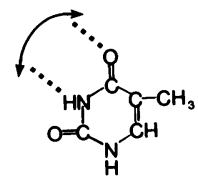

Thymine

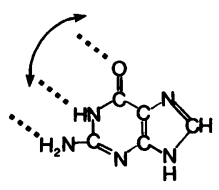

Guanine
Figure 7. Schematic diagram of the putative epitopes recognized on purine and pyrimidine bases.

Structures of the bases are those in aqueous solutions on $\mathrm{pH}$ 7. Dotted lines represent positions involved in hydrogen bonding formation of the right-handed dsDNA helix. Arrows indicate the presumed target determinants capable of interacting with the combining site of the anti-DNA antibodies described herein. 
but distinct populations reacting with conjugates of other nucleosides were also present $(6,32)$. Conjugation of nucleoside or nucleotide was required for a reaction of measurable affinity in our assays. Similarly, free nucleosides or mononucleotides often bind only at high concentrations, if at all, to SLE serum antibodies (30). When nucleosides and nucleotides are presented on macromolecule carriers, the great increase in binding suggests that the optimal determinant is larger than the base of a single nucleoside and/or that bivalent binding of antibody to one molecule of antigen is required for measurable affinity.

$\operatorname{Poly}(\mathrm{dT})$, poly $(\mathrm{G})$ or poly(dG), and poly(I) are also prominent among polynucleotides that react well with monoclonal autoantibodies from both human and murine subjects with SLE $(6,7,33-35)$. Guanine and thymine are prominent as components of nucleotides and oligonucleotides that react with certain of the antibodies $(6,7,33-35)$.

Another indication for similarity of myeloma proteins and lupus anti-DNA autoantibodies comes from idiotypic analysis. Certain idiotypes have been found to recur among lupus antiDNA autoantibodies (36-38). Anti-DNA-related idiotopes were also described among certain Waldenström's proteins (14) and among two of the HMP described in this report (12). More recently it was shown that lymphocytes of normal individuals can be stimulated by pokeweed mitogen to produce immunoglobulins with idiotypic determinants shared by SLE-derived monoclonal antibodies (39). Thus, patients with lymphoproliferative diseases and some normal persons can express a conserved set of idiotopes that are also found on immunoglobulin molecules present in lupus.

Although the binding specificities of the myeloma proteins described in this study are similar to those of the most frequently occurring SLE antibodies to DNA, none of the patients with these myeloma proteins showed any clinical expression of SLE. Recently a monoclonal immunoglobulin isolated from a patient with Waldenström's macroglobulinemia but devoid of SLE was reported to exhibit anti-dsDNA activity (13). These observations together with previous reports $(9,12)$ are puzzling in view of the "pathogenic" role of anti-DNA antibody in SLE. Two nonmutually exclusive possibilities may explain this disparity between the occurrence of anti-DNA antibodies and their pathogenic role. It may be that undetermined factors other than the presence of anti-DNA antibodies are required for clinical expression of SLE. These factors could be absent in normal individuals and in patients with lymphoproliferative diseases. Alternatively, it is possible that pathogenic anti-DNA antibodies originate from distinct genetic elements and/or from different clonotypes. Determination of the primary amino acid sequence of the variable region of such HMP and identification of the variable genes expressed by human anti-DNA antibodies from SLE patients will help to clarify this fundamental issue.

\section{Acknowledgments}

We are indebted to Dr. Jean-Marius Fine for his generous gift of human myeloma proteins. We also thank Ann Abdelrazzaq for editorial assistance.

This work was supported by a National Institutes of Health John E. Fogarty International Fellowship (IFO5TW-1862) to Dr. M. Zouali and by grant AI 19794 from the National Institute of Allergy and Infectious Diseases.

\section{References}

1. Koffler, D. 1974. Immunopathogenesis of systemic lupus erythematosus. Annu. Rev. Med. 25:149-164.
2. Tan, E. M. 1982. Autoantibodies to nuclear antigens (ANA): their immunobiology and medicine. Adv. Immunol. 33:167-240.

3. Stollar, B. D. 1981. Anti-DNA antibodies. Clinics Immunol. Allergy. 1:243-260.

4. Lafer, E. M., J. Rauch, C. Andrzejewski, Jr., D. Mudd, B. Furie, B. Furie, R. S. Schwartz, and B. D. Stollar. 1981. Polyspecific monoclonal lupus autoantibodies reactive with both polynucleotides and phospholipids. J. Exp. Med. 153:897-909.

5. Koike, T., H. Tomioka, and A. Kumagai. 1982. Antibodies crossreactive with DNA and cardiolipin in patients with systemic lupus erythematosus. Clin. Exp. Immunol. 50:298-302.

6. Munns, T. W., M. K. Liszewski, and B. H. Hahn. 1984. Antibodynucleic acid complexes. Conformational and base specificities associated with spontaneously occurring poly- and monoclonal anti-DNA antibodies from auto-immune mice. Biochemistry. 23:2964-2970.

7. Shoenfeld, Y., J. Rauch, H. Massicotte, S. K. Datta, J. AndreSchwartz, B. D. Stollar, and R. S. Schwartz. 1983. Polyspecificity of monoclonal lupus autoantibodies produced by human-human hybridomas. N. Engl. J. Med. 308:414-420.

8. Sasaki, T., F. Endo, M. Mikami, Y. Sekiguchi, K. Tada, Y. Ohno, N. Ishida, and K. Yoshinaga. 1984. Establishment of human monoclonal anti-DNA antibody-producing cell lines. J. Immunol. Methods. 72:157165.

9. Seligmann, M., and J. C. Brouet. 1973. Antibody activity of human myeloma globulins. Semin. Hematol. 10:163-177.

10. Freedman, M. R., R. Merrett, and W. Pruzanski. 1976. Human monoclonal immunoglobulins with antibody-like activity. Immunochemistry. 13:193-202.

11. Dighiero, G., B. Guilbert, J. P. Fermand, P. Lymberi, F. Danon, and S. Avrameas. 1983. Thirty-six human monoclonal immunoglobulins with antibody activity against cytoskeletal proteins, thyroglobulin, and native DNA: immunologic studies and clinical correlations. Blood. 62: 264-270.

12. Zouali, M., J. M. Fine, and A. Eyquem. 1984. Anti-DNA autoantibody activity and idiotypic relationships of human monoclonal proteins. Eur. J. Immunol. 14:1085-1089.

13. Fermand, J. P., F. Danon, and J. C. Brouet. 1985. Characterization of a human monoclonal IgM with antibody activity to dsDNA. Clin. Exp. Immunol. 59:467-474.

14. Naparstek, Y., D. Duggan, A. Schattner, M. P. Madaio, B. D. Stollar, E. A. Kabat, and R. S. Schwartz. 1985. Immunochemical similarities between monoclonal antibacterial Waldenstrom's macroglobulins and monoclonal anti-DNA lupus autoantibodies. J. Exp. Med. 161:15251538.

15. Zouali, M., J. M. Fine, and A. Eyquem. 1984. A human monoclonal IgG1 with anti-idiotypic activity against anti-human thyroglobulin autoantibody. J. Immunol. 133:190-194.

16. Papalian, M., E. Lafer, R. Wong, and B. D. Stollar. 1980. Reaction of systemic lupus erythematosus antinative DNA antibody with native DNA fragments from 20 to 1,200 base pairs. J. Clin. Invest. 65:469474.

17. Stollar, V., T. E. Shenk, and B. D. Stollar. 1972. Double-stranded RNA in hamster, chick, and mosquito cells infected with Sindbis virus. Virology. 47:122-132.

18. Erlanger, B. F., AND S. M. Beiser. 1964. Antibodies specific for ribonucleosides and ribonucleotides and their reaction with DNA. Proc. Natl. Acad. Sci. USA. 52:68-74.

19. Stollar, B. D. 1980. The experimental induction of antibodies to nucleic acids. Methods Enzymol. 70:70-85.

20. Seligmann, M. 1957. Mise en évidence dans le sérum de malades atteints de lupus érythémateux disseminé d'une substance déterminant une réaction de précipitation avec l'acide désoxyribonucleique. $C . R$. Acad. Sci. Paris. 245:243-245.

21. Cepellini, R., C. Polli, and F. Celada. 1957. A DNA-reacting factor in serum of a patient with lupus erythematosus diffusus. Proc. Soc. Exp. Biol. Med. 96:572-574.

22. Robbins, W. C., H. R. Holman, H. R. Deicher, and H. G. Kunkel. 
1957. Complement fixation with cell nuclei and DNA in lupus erythematosus. Proc. Soc. Exp. Biol. Med. 96:575-579.

23. Miescher, P., and R. Strassle. 1957. New serological methods for the detection of the lupus erythematosus factor. Vox. Sang. 2:283-287.

24. Stollar, D., L. Levine, and J. Marmur. 1962. Antibodies to denatured deoxyribonucleic acid in lupus erythematosus. II. Characterization of antibodies in several sera. Biochim. Biophys. Acta. 61:7-18.

25. Arana, R., and M. Seligmann. 1967. Antibodies to native and denatured deoxyribonucleic acid antigens in systemic lupus erythematosus. J. Clin. Invest. 46:1867-1882.

26. Stollar, D., L. Levine, H. I. Lehrer, and H. Van Vunakis. 1962. The antigenic determinants of denatured DNA reactive with lupus erythematosus serum. Proc. Natl. Acad. Sci. USA. 48:874-880.

27. Stollar, D., and L. Levine. 1963. Antibodies to denatured deoxyribonucleic acid in lupus erythematosus serum. IV. Evidence for purine determinants in DNA. Arch. Biochem. Biophys. 101:417-422.

28. Picazo, J. J., and E. M. Tan. 1975. Specificities of antibodies to native DNA. Scand. J. Rheumatol. Suppl. 11:35-41.

29. Stollar, B. D., and M. Papalian. 1980. Secondary structure in denatured DNA is responsible for its interaction with anti-native DNA antibody of systemic lupus erythematosus sera. J. Clin. Invest. 66:210219.

30. Casperson, G. F., and E. W. Voss, Jr. 1983. Specificity of antiDNA antibodies in SLE-II. Relative contribution of backbone, secondary structure, and nucleotide sequence to DNA binding. Mol. Immunol. 20: 581-588.

31. Alarcon-Segovia, D., E. Fishbein, H. Alcala, E. Olguin-Palacios, and S. Estrada-Parra. 1970. The range and specificity of antinuclear an- tibodies in systemic lupus erythematosus. Clin. Exp. Immunol. 6:557571.

32. Weisbart, R. H., G. Chan, A. Kacena, and R. E. Saxton. 1984. Characterization of mouse and human monoclonal antibodies crossreactive with SLE serum antibodies to guanosine. J. Immunol. 132:29092912.

33. Andrzejewski, C., J. Rauch, E. Lafer, B. D. Stollar, and R. S. Schwartz. 1981. Antigen-binding diversity and idiotypic cross-reactions among hybridoma autoantibodies to DNA. J. Immunol. 126:226-231.

34. Lee, J. S., J. R. Lewis, A. R. Morgan, T. R. Mosmann, and B. Singh. 1981. Monoclonal antibodies showing sequence specificity in their interaction with single-stranded DNAs. Nucleic Acids Res. 9:1707-1721.

35. Eilat, D., S. A. Ben Sasson, and R. Laskov. 1980. A ribonucleic acid-specific antibody produced during autoimmune disease: evidence for nucleotide sequence specificity. Eur. J. Immunol. 10:841-845.

36. Solomon, G., J. Schiffenbauer, H. D. Keiser, and B. Diamond. 1983. Use of monoclonal antibodies to identify shared idiotypes on human antibodies to native DNA from patients with systemic lupus erythematosus. Proc. Natl. Acad. Sci. USA. 80:850-854.

37. Shoenfeld, Y., D. A. Isenberg, J. Rauch, M. P. Madaio, B. D. Stollar, and R. S. Schwartz. 1983. Idiotypic cross-reactions of monoclonal human lupus autoantibodies. J. Exp. Med. 158:718-730.

38. Zouali, M., and A. Eyquem. 1984. Idiotype restriction in human autoantibodies to DNA in systemic lupus erythematosus. Immunol. Lett. 7:187-190.

39. Datta, S. K., Y. Naparstek, and R. S. Schwartz. 1986. In vitro production of an anti-DNA idiotype by lymphocytes of normal subjects and patients with systemic lupus erythematosus. Clin. Immunol. Immunopathol. 38:302-318. 